\title{
5 Years After Tragedy: An Update on Organ Procurement Travel in Michigan
}

\section{To the Editor:}

In 2007, six members of a lung procurement team from the University of Michigan were killed in a plane crash over Lake Michigan. In response, The Michigan Donor Travel Forum assembled to develop strategies for improving the safety of procurement travel in the United States. Several issues were identified as targets for future quality improvement, including concerns of safety culture, communication between stakeholders and standardization of travel practices (1) (Table 1). Here, we revisit the Michigan Donor Travel Forum's recommendations and evaluate our center's response in an effort to promote ongoing dialog related to procurement travel practice reform.

The 2009 Forum concluded that current organ procurementrelated travel practices are inefficient and frequently involve multiple teams traveling significant distances to the donor hospital. Limiting transplant team travel may have significant benefit for improving safety-particularly in cases where fixed-wing aircraft is necessary. Possible solutions included utilization of a centralized procurement facility and/or procurement by local transplant surgeons $(2,3)$. At our institution, these two practices have led to a measurable decrease in procurement-related travel. We employed one of these techniques for $25 \%$ of liver procurements during a recent 18-month period. In turn, we appreciated an overall savings of 2058 nautical miles and a 16\% reduction in procurement team travel. These savings particularly reduced fixed-wing aircraft travel. Intuitively, reduction of air travel can also result in cost savings for transplant centers and Organ Procurement Organizations (OPOs) coordinating these services.

Tangible manifestations of safety culture are difficult to identify. We revisited flight charter services and specifically informed contract decisions based on safe operating practices and reputation. Cost considerations received secondary preference. We restructured our institution's liability insurance coverage to more appropriately reflect the scope and volume of our center. These measures highlight an increased focus on preventative and preparatory measures related to transplant travel. Importantly, addressing these factors requires little in the way of operational policy or structural changes within a transplant program.

Since our accident in 2007, the transplant community experienced three more procurement-related fatalities following a 2011 helicopter crash in Florida. Formal investigation by the National Transportation Safety Board implicated poor flight planning and pilot decision-making in the event. Reexamination of current practices is critical at this time. We believe that understanding the geographic differences within and between donor service areas is paramount to improving the efficiency of the donor procurement operation. Consideration of this information has informed practice changes at our transplant center. The availability of procurement data has also received little attention at the local, regional or national scale since 2009. Given that approximately $75 \%$ of OPOs coordinate procurement travel, we believe that documentation of travel practices should occur at this level.

More work is necessary in order to align procurement travel expectations with the high standards that permeate all other aspects of transplantation. Critical barriers to change exist (Table 1). Transplant centers must work together, potentially under the guidance of a dedicated procurement safety organization, to find creative solutions to advance safety culture, optimize efficiency and improve data collection.

Table 1: Key issues raised by the Michigan Donor Travel Forum in 2009

Issue \#1 $\begin{aligned} & \text { The currently available data on organ procurement practices are inadequate } \\ & \text { Barriers to improvement: Systematic data collection is cumbersome and there is no central repository for such information } \\ & \text { at this time }\end{aligned}$
$\begin{gathered}\text { Operators currently contracted for transplant travel vary dramatically in terms of aircraft, pilot qualifications and safety } \\ \text { certifications } \\ \text { Barriers to improvement: There are no established national standards available to transplant programs to inform travel } \\ \text { contract agreements }\end{gathered}$
$\begin{gathered}\text { Current organ procurement travel practices are inefficient } \\ \text { Barriers to improvement: Coordination and centralization of procurement practices currently rely on individual transplant } \\ \text { centers efforts } \\ \text { Lack of standards for organ procurement insurance and travel liability coverage } \\ \text { Barriers to improvement: Gaps in knowledge and accurate cost information are largely unavailable to transplant centers }\end{gathered}$
Issue \#4




\section{Sheetz et al.}

K. H. Sheetz ${ }^{1}$, W. J. Kanitz' ${ }^{2}$ M. J. Englesbe ${ }^{1}$ and S. A. Waits ${ }^{1, *}$ ${ }^{1}$ Department of Surgery, University of Michigan Ann Arbor, M

${ }^{2}$ College of Medicine and Life Sciences, University of Toledo Toledo, $\mathrm{OH}$

${ }^{*}$ Corresponding author: Seth A. Waits, waitss@med.umich.edu

\section{Disclosure}

The authors of this letter to the editor have no conflicts of interest to disclose as described by the American Journal of Transplantation.

\section{References}

1. Englesbe MJ, Shah S, Cutler JA, et al. Improving organ procurement travel practices in the United States: Proceedings from the Michigan Donor Travel Forum. Am J Transplant 2010; 10: 458-463.

2. Moazami N, Javadi OH, Kappel DF, Wagner J, Jendrisak MD. The feasibility of organ procurement at a hospital-independent facility: A working model of efficiency. J Thorac Cardiovasc Surg 2007; 133: 1389-1390

3. Shiraishi Y, Ochoa L, Richardson G, et al. Retrieval by other procurement teams provides favorable lung transplantation outcome. Ann Thorac Surg 1997; 64: 203-206. 